\title{
A Tentative Research on Education of Sense of Identity of Citizenship in Singapore
}

\author{
Yongli Liu \\ School of Mathematical Sciences, Qufu Normal University \\ No. 57, Jingxuan West Road, Qufu 273165, Shangdong, China \\ E-mail: billy52@126.com \\ Wanmin Wang \\ College of Education Science, Qufu Normal University \\ No. 57, Jingxuan West Road, Qufu 273165, Shangdong, China \\ E-mail: qufuwwm2003@tom.com
}

\begin{abstract}
Sense of identity among citizens is an issue that is generally concerned and tried to resolve by all countries all over the world nowadays. A general view of the development history of Singapore, it is discovered that economic boom and harmony of the society in Singapore benefits from cultivation of the sense of identity of citizenship. The reform and opening up of China for almost thirty years has brought tremendous social changes, and simultaneously has led to crisis in identity of citizenship. Successful practices and experiences in Singapore to intensify the core of "awareness of the nation" and conduct education of sense of identity among citizens have important guidance value and reference significance to establishment of a harmonious society in China.
\end{abstract}

Keywords: Singapore, Identity of citizenship, Education

Singapore is reputed as "one of the most mannered cities in the world" and "a model of East Asian modern civilization" owing to its social progress and high civilization, with terms of "Asian Four Dragons" and "Asian Monaco". However, at the beginning of its founding, Singapore was an island country lacking in resources and unrest in politics. The reason why Singapore could arise in Southeast Asia and become a "commercial Bliss country" with stable politics and developed economy just "as a phoenix that could rise from the ashes" is that, Singapore has conducted education of sense of identity among citizens without a break and with great efforts in the process of modernization, which has finally enabled people from different races to recognize Singapore in their mind and struggle for prosperity of Singapore. For the time being, China is at a stage of establishing a harmonious society, so research and reference of the successful experiences of education of sense of identity in Singapore will have an important guidance effect upon establishment of the harmonious socialism society.

\section{Historical background of education of sense of identity among citizens in Singapore}

\subsection{Singapore is a nation which suffered from a long history of rule by colonists}

In August 1965, Singapore declared the founding of the Republic. Earlier, Singapore was descended to the British colony for more than one hundred years, and was for a while forcibly occupied by Japan in the 40s of the Twentieth Century. Different Suzerain States brought to Singapore different social systems, cultures, styles of life and concepts of value. This unfortunate history caused chaos of identity of the citizens in the nation and the government.

\subsection{Singapore is a typical nation of immigrants}

In the beginning, there are a majority of aboriginals among Singaporean citizens, and most of the people are immigrants and their descendants who have immigrated from Asia and Europe, etc, in the recent one hundred years. In the lengthy historical progress, these immigrants and their descendants have made positive contributions to exploiting, constructing and developing Singapore. However, they have had close cultural origins in the country of residence and embraced strong emotion towards it, whereas Singapore is no more than "a strange foreign country" to them. Hence, at the beginning of the founding of Singapore, "it was really difficult 
to generate a sense of identity between the people and the land and between the people and the government, lacking a strong patriotism enthusiasm."

\subsection{Singapore is a typical diversified society}

The global immigration led to the social situation in which Singaporean diversified races and diversified values co-existed. Diversified races have brought about diversified religious believes. Singapore is one of the countries in the world that have the most complicated religious and linguistic structure. This sort of diversified social structure is more likely to cause racial prejudice and religious confrontation.

It is just based on this historical background and social reality that Singapore was dedicated to education of the sense of identity among citizens for a long time after its founding and concentrated on cultivation of the awareness of the nation in its citizens.

\section{Major measures taken by Singapore to conduct education of sense of identity among citizens}

\subsection{Inculcation of the awareness that "I am a Singaporean"}

According to Singaporean Government, under such a historical background with diversification of ethnic groups, religions and concepts of value, the first thing to do is to cultivate the sense of belonging and sense of identity among its citizens, enabling them to transfer from the sense that "I am a Chinese (or Malayan or Indian) in the terms of form and psychology to the sense that "I am a Singaporean", and to recognize the newly born country. Thus, after the founding of the country, the government has all along inculcated the awareness that "I am a Singaporean" by means that can be accepted by all nationalities.

What is "Singaporean"? According to Lee Kuan Yew, "Singaporean is one who is born, grows or resides in Singapore and who is willing to maintain the multi-racial, magnanimous, accommodating and forward-looking society, prepared at all times to be dedicate themselves to it". Specifically speaking, "a Singaporean" should have the following quality: awareness of the nation, correct values, ideal moral integrity, ability to distinguish right from wrong and to resist western decadent ideological trends and rotten spiritual life. To inculcate the awareness that "I am a Singaporean" is to ultimately enable people to recognize in their mind that Singapore is the nation which they themselves depend on.

\subsection{Creation of the characteristic "Singaporean culture"}

In the modernization process of "high speed trains", Singapore is faced up with confrontation between eastern culture and western culture. Young people attach too much importance to material life and personalism, and are lacking in the spirit to get ready to help others for a just cause, regardless of interests of the society and the nation. In face of such a social status quo, the government appeals to the whole society to bear in mind the Asian attribute of Singaporean culture at the time of learning western science and technology. That is to say, "modernization should not be at the cost of losing oneself and modernization is not equal to westernization". Although the major ethnic groups in Singapore have age-old and brilliant historical culture, a leading social culture has not been generated. Therefore, when the Singaporean Government respects culture of all ethnic groups, it also proposes creation of a characteristic "Singaporean culture".

The central content of "Singaporean culture" is to endow explanation of modernization and localization with the "Eight Virtues" in Confucianism, namely, "loyalty, filial piety, kindheartedness, love, propriety, justice, honesty and honour". This culture combines the ethnical concept of Confucianism, tradition of Malay and the ethos of Indian together with the "scientific survey method of western people to dive to the bottom and the inference method of objectively seeking for truth". Thus, it is a cultural value system which not only be recognized and accepted by eastern countries and all ethnic groups, but can also play a role in resisting western rotten culture and values.

\subsection{Reinforcement of education on "awareness of the nation"}

In 1981, Lee Kuan Yew put forward the slogan of "one nation, one country and one Singapore", and encouraged his citizens not to be restricted by a certain race or religion, but to struggle together for a common country. In October 1988, the Prime Minister Goh Chok Tong formally put forward the recommendation of developing "awareness of the country", and termed it as "a common view of value appraised and lived on by Singaporeans of all races and religions". In view of this, Singapore proposed a presupposition to set up a "common view of value" that could represent common interests of different races, religions and groups and could be identified by people of all races and religions. "These rules, views of value and doctrines could mould complete Singaporeans in the future". In January 1991, Singaporean Government formally released "White book for Common View of Value", and summarized the common view of value as the situation of "nation before community and society 
above self, family as the basic unit of society, regard and community support for the individual, consensus instead of contention, racial and religious harmony." "Common view of value" contains the awareness of belonging, awareness of the interest of the country first and awareness of "group", namely, collective spirit, and its core is to cultivate and strengthen "awareness of the country" and to educate citizens, especially young people, to put interests of the country and the society before individual interest, with the ideal of establishing a harmonious society. It has been proven by history that, "common view of value" has provided vigorous spiritual support for economic boom and wealth and power of the nation in Singapore.

\section{Primary approaches to education of sense of identity among citizens in Singapore}

\subsection{Establishment of "Committee of Awareness of Nation" to positively create a social atmosphere of cultivating sense of identity among Singaporean citizens}

Singapore attaches great importance to creating a state of mind of "Singaporean" recognized by all citizens. Since the end of 1970s, Singaporean Government has conducted extensively all over the country education on "awareness of the country" in all sorts of forms.

The government set up the "Committee of Awareness of Nation" to cultivate the "awareness of the nation" among its citizens. Since 1988, all citizens, no exception to old and young people, have started to participate in the activity of "Week of Awareness of the Nation" each year. At the ceremony of raising the national flag, all citizens have to take a collective oath, "We are Singaporean citizens, with no distinction of race, language and religion, united as one, and we should make efforts together in order to establish a fair and equal domestic society and realize the happiness, prosperity and progress of the country". Through this, the government intensifies the sense of identity and sense of belonging in Singapore among its citizens.

\subsection{Emphasis on moral education in schools to cultivate the sense of identity in Singapore among students}

According to the Government of Singapore, one of the most approaches to overcome the state of mind of immigration, diverse races and diverse religions is to conduct education in schools that "I am a Singaporean", and enable students to establish a sense of identity, sense of belonging and sense of responsibility in the nation at an early age. Therefore, Singaporean Government attaches great importance to this primary channel of moral education in schools and puts great focus on moral education from the nursery school stage of a citizen until his/her university period.

In the second year after independence of Singapore, the government issued the general outline about moral education in schools and training of citizens, and exercised civic education, with a focus on cultivating the "awareness of the nation" among students. That is to say, to teach students to recognize the country and its interests, defend interest of the country and strengthen their social responsibility to be a qualified citizen. Since the 70s in the Twentieth Century, although design of courses of moral education and names of these courses have undergone reform and changes for several times, the moral education has always been emphasizing significance and necessity of cultivating students' "awareness of the nation". Since the year 1980, Singapore ha made an overall reflection upon moral education in schools and worked out for the second time the plan of moral education in schools, especially concentrating on inculcation of the ethical values of Confucianism to students, with the same purpose of cultivating students" "awareness of the nation", correct view of value, the ability to distinguish right from wrong and resist influences of western decadent ideas. After 1990s, Singapore again made a new adjustment to design of moral education in primary and junior schools based on the centre of "common view of value", with a focus on cultivating students' awareness of the nation, awareness of citizenship, awareness of cooperation and awareness of tolerance, and a focus on education of public virtue and family virtues, etc.

\subsection{To bring into play the role of a family and a community and to cultivate the belief in "home" of a citizen}

It comes to the Singaporean government that, in order to overcome the state of mind of immigration among citizens, and make them really take Singapore as their own "home", reduce their feeling of inquilinism and strengthen their sense of belonging, the best to do is to provide them with a "nest" of their own, because "those with immovable properties are persistent, and living in peace to work in contentment". Hence, Singaporean government has started up the "Home Ownership Scheme" which has already been implemented for thirty years in order to resolve the housing issue for its ordinary people. At the same time, the government also focus on measures of legislation and directing of policies to maintain integrity of a family. Lee Kuan Yew also emphasized, "in the process of modernization, .... We can, by no means, let families separated which have three generations under one roof," and "if we can keep this family system of such a family structure, then our society will be a more happy and beautiful society." Hence, harmony of a family is the basic view of value for Singapore 
to maintain its social subsistence and development.

In addition, Singaporean Government also cultivates the sense of belonging of citizens in the community by means of strengthening community construction and finally achieves the target of cultivating their sense of identity in the country. Since the beginning of 1977, Singaporean Government has popularized and set up residential committees at non-mature estates which are regarded as the battle field for cultivation of the sense of identity among citizens. "In the 1980s, there was not any other community organization than residential committee which played a more important role... A residential committee could gather together formerly strange neighbours to communicate feelings, which would promote the spirit of good-neighbourliness." A residential committee is not purely a convenience-for-people institution, but an approach to breed and cultivate a community spirit so as to eliminate alienation brought about by social industrialization between human beings.

3.4 To respect religious belief of citizens and to carry out the policy of harmonious co-existence of all races and religions

Religion is one of the primary sources for Singaporean value concepts and social responsibility. "In Singapore, religion plays a positive role and a religious group has always been making great contributions to the country. Singaporeans acquire spiritual strength and moral guidance from their religious belief'. It is just because of this that the government especially respects the religious belief of its citizens, carries out enlightened, equal, neutral and loose policies towards a religious group, encourages each minority to maintain and manifest their own culture and religion, and largely supports and guides the religious group and religious people to take positive participation in charity, education and social service. Harmony of races and religions is the base for subsistence of Singapore. The government carries out the policy of "harmony of races and tolerance of religions", and emphasizes cross-bench mind to all nationalities and that all are equal before opportunities of education and employment, etc. The government advocates protection of interests of the ethnic minorities. For the time being, sanguinary conflict incidents and wars are common occurrence caused by disputes and contradictions between diverse ethnic groups and religions in many countries and regions in the world. However, since its independence in 1965, there almost has not had any religious conflict in Singapore and all religious organizations and groups have shown mutual respect and got together in harmony.

\section{Enlightenment of education of the sense of identity of citizenship in Singapore}

\subsection{Cultural identity is the foundation for education of the sense of identity of citizenship.}

In the contemporary world, culture more and more becomes a primary source for national cohesion and creation, and more and more becomes an important factor for competition in overall national strength. Experiences in Singapore prove that, the national character of culture is the root and pulse for cultural identity, whereas cultural identity is the foundation for education of the sense of identity among citizens. Currently, China is in a process of social transition and rapid economic development, and is likewise faced up with collision and conflict of eastern and western culture. Thus, for China, cultural identity also has significant strategic meaning.

\subsection{The "awareness of the nation" is the core of education of the sense of identity of citizenship.}

At present, all countries in the world regard inculcation of "the awareness of the country" as the spiritual basis for education of patriotism. In order to cultivate the "awareness of the country" among its citizen, on one hand, Singaporean Government seeks for a point of combination of interests of the country and individuals, and on the other hand, integrates the "awareness of the country" into daily life of the citizens. Singapore is used to reaffirming the foundation to build the country, "awareness of the country" in important festivals, such as National Day, New Year's Day and the Spring Festival, etc. "Society overtopping individuals" is one of the basic value decrees for Singapore to maintain its national subsistence and development. The above practices and experiences tell us that, cultivation of the "awareness of the country", maintenance of unification and solidarity of all races and protection of the national interests is all along the focus for education of patriotism. Development of the economic society requires for vigorous reinforcement of the education of "awareness of the country" and the concept of "the country overtopping everything" should also become the common view of value for Chinese people.

4.3 Moral education in schools is the primary channel to conduct education of the sense of identity of citizenship.

At all times and in all over the world, any ethnic group and country regards moral education in schools as the primary channel for education of the sense of identity among its citizens. Singapore has eventually evolved from a country with a combination of diverse races and diverse cultures to one prosperous and harmonious "ethnic group, country and Singapore". Moral education in schools has played a historical active role. "After its 
independence, the awareness of the country among Singaporeans has been established initially." It has been proved by history that, moral education in schools in Singapore is highly effective. However, a general view at the status quo of moral education in schools in China, it is indicated through education in the recent several decades that, China makes too much of exam-oriented education, which makes moral education in schools descend to inculcation of forms and emptiness and difficult to assume the historical responsibility for cultivating identity of the nation and the country among young people. Experiences of Singapore tell us that, cultivation of the awareness of the identity of the nation and the country among citizens has to start with youngsters.

\subsection{Family and community are the base for education of the sense of identity of citizenship}

"A family is the core of the society", which is taken by Singapore as one of the basic value decrees to maintain social subsistence and development. The government maintains integrity of a family by several means, such as legislation and policy orientation, etc. For example, in the aspect of housing distribution, the government gives preference of price to families of three generations under one roof and prioritizes housing to them. In the aspect of taxation, houses handed down from parents can be conditionally remitted of estate duty, etc. It is via the approach of family that Singapore enables values of traditional culture to be handed down from parents to the next generation without any conscious influence and carried forward. Of course, construction of the community is also an important channel for Singapore to keep its social stability and enhance its social cohesion. Quite a large number of facts have proven that, family education and community construction in Singapore not only strengthens the sense of belonging of residents in the family and community, but also improves the reliability of citizens in the government and identity of the country.

4.5 Issues related to the welfare and well-being of the people is the social guarantee for education of the sense of identity of citizenship.

In the process of rapid economic development, Singapore has worked out and carried out a series of policies and measures to care about and resolve issues of the people's livelihood. For instance, all the following practices have played a guarantee role in cultivating and strengthening citizens' identity of the country: smoothing the channel for the will of the people to appeal, maintaining the harmonious relationship between young people and senior citizens, establishing a kind relationship between those successful and unsuccessful, and positive implementation of many plans, such as, "home ownership scheme", renovation of old housing estates, possession of stocks, public accumulation funds and Medisave by all citizens.

To sum up, the issue of identity under a globalization circumstance is a general concern of the current society and an important subject which the whole world puts forth efforts to resolve. Singapore is established into a globally recognized harmonious society through education of the sense of identity among its citizens with the core of "awareness of the country". It has been proven by facts that, the sense of identity among citizens has the effect of consolidating power, converging emotion and promoting development of the society. The reform and opening up in China for almost 30 years has not only brought tremendous changes to the entire society, but has also led to crisis of the citizens in identity of the government and the society. Especially, in the process of urbanization construction, quite a huge number of "urban immigrants" have appeared, and their situation and state of mind is quite similar to that of immigrants at the beginning of the founding of Singapore. According to the theory by the American scholar Francis Fuknyama, when people set up for their life, their thirst to "acquire recognition" will be extremely strong. A lot of conflicts in history were not for "existence", but for "acquisition of recognition". Therefore, it is a social issue for China to take into consideration in the process of establishing a harmonious society to improve citizens' identity of a country and immigrants' identity of a city.

\section{References}

Chen, Junke. (2002). The Features of Moral Education in Japanese and Singapore Schools. Comparative Education Review, (10).

Chen, Lisi. (1999). Ideological and Political Education in the Modern World. Beijing: China Renmin University Press.

Feng, Zengjun \& Wang, Xuefeng, et al. (1999). Study on Moral Education in Schools of the Asian Four Dragons. Fuzhou: Fujian Education Press.

Hua, Yan. (1993). Brief Analysis of the Diversified Religious Policy by the Singaporean Government. Southeast Asian Studies, (3).

Lei, Yi. (2006). For Acquisition of Recognition. South Weekend, Nov., 9.

Liu, Zizun \& Kong, Lin. (2003). The Ideological and Political Education in Singapore and the Enlightenment. Journal of Ideological \& Theoretical Education, (7).

Wang, Fan. (2003). Singapore's Moral and Ethic Education and the Enlightenment. Guangxi Social Sciences, (4). 